\title{
Expression of $G A D 67$ and Novel GAD67 Splice Variants During Human Fetal Pancreas Development
}

\author{
GAD67 Expression in the Fetal Pancreas
}

\author{
Esther Korpershoek • Aart M. Verwest • \\ Ynske IJzendoorn • Robbert Rottier • \\ Hemmo A. Drexhage $\cdot$ Ronald R. de Krijger
}

Published online: 16 May 2007

(C) Humana Press Inc. 2007

\begin{abstract}
Glutamic acid decarboxylase $(G A D)$ is a major inhibitory neurotransmitter in the brain, which catalyses the reaction of L-glutamate to $\gamma$-aminobutyric acid. There are two isoforms of $G A D$, a $65-\mathrm{kDa}$ form and a $67-\mathrm{kDa}$ form, which are encoded by two different genes. As previous studies suggested a role for GAD67 splice variants during fetal pancreas development, we have investigated the mRNA expression of GAD67 and GAD67 splice variants in a series of 14 human fetal pancreases between 14 weeks gestation and term and in adult control pancreases by RTPCR. In this study, we demonstrate mRNA expression of GAD67 and four GAD67 splice variants, including GAD25, in human fetal and adult specimens. Some of the splice variants, including various proportions of exon 7 or a new exon between exons 6 and 7, have not been described
\end{abstract}

E. Korpershoek · Y. IJzendoorn · R. R. de Krijger $(\bowtie)$ Department of Pathology, Josephine Nefkens Institute, Room 222, Erasmus MC-University Medical Centre Rotterdam, P.O. Box 2040, Dr. Molenwaterplein 50, 3000 CA Rotterdam, The Netherlands e-mail: r.dekrijger@erasmusmc.nl

\section{A. M. Verwest}

Department of Paediatrics, Erasmus MC-Sophia, Dr. Molenwaterplein 50,

Rotterdam, The Netherlands

R. Rottier

Department of Paediatric Surgery and Cell Biology and Genetics, Erasmus MC-Sophia, Dr. Molenwaterplein 50,

Rotterdam, The Netherlands

H. A. Drexhage

Department of Immunology, Erasmus MC-University Medical Centre Rotterdam, Dr. Molenwaterplein 50,

Rotterdam, The Netherlands before in the human pancreas. We speculate that the expression of these GAD67 splice variants might be related to human fetal pancreas development.

Keywords fetal development $\cdot G A D \cdot$ pancreas alternative splicing $\cdot$ human development

\section{Introduction}

Two forms of glutamic acid decarboxylase $(G A D)$ occur in mammalian tissues: a $65 \mathrm{kDa}$ form $(G A D 65)$ and a $67-\mathrm{kDa}$ form (GAD67). GAD65 and GAD67 are enzymes that catalyze the reaction of L-glutamate to $\gamma$-aminobutyric acid, a major inhibitory neurotransmitter in the central nervous system. The two $G A D$ isoforms are highly homologous but are encoded by separate genes [1]. GAD65 is localized on chromosome 10, and GAD67 on chromosome 2 [2]. Alternative splicing of the GAD67 gene can result in two additional isoforms of the protein [3, 4].

In humans, autoreactivity against GAD is often found in type 1 diabetes mellitus. Some 10 to $30 \%$ of the newly diagnosed patients have GAD67 antibodies, and up to $80 \%$ have GAD65 antibodies. Because the prevalence of GAD67 autoreactivity is less than GAD65, and is usually detected in patients with GAD65 antibodies, the GAD67 antibodies are assumed to play a less prominent role in the pathogenesis of $\beta$-cell destruction [3]. However, there are studies where GAD67 reactivity was found in patients without reactivity against GAD65 [5-7].

GAD65 and GAD67 are both highly expressed in the brain, but the two forms appear to be differentially expressed in pancreatic islets. In human islets, GAD65 is 
abundant, but GAD67 could not be detected with immunohistochemistry, in situ hybridization, immunoprecipitation, or Western blotting [3,8-10]. In one study, limited GAD67 expression was demonstrated in human islets by RNase protection analysis [11]. In contrast, rat islets express both forms, whereas mouse islets express predominantly GAD67 $[4,8,10,12,13]$.

In addition to the native form of GAD67, of which exon 7 is spliced out of the mRNA, other forms of alternative splicing of the GAD67 gene have been described in the rodent brain. This alternative splicing resulted in two additional $G A D$ transcripts in which either the first 80 or the first 86 bp of exon 7 were inserted into the full length GAD67 message, respectively [4, 14]. Transcripts with the 80-bp insertion result in two overlapping open reading frames, encoding an enzymatically inactive $25-\mathrm{kDa}$ protein $(G A D 25)$ and an enzymatically active $44-\mathrm{kDa}$ protein (GAD44). A second stop codon at the end of the 86-bp insertion abolishes the translation of GAD44 (Fig. 1A). This alternative splicing was only observed in embryonic and fetal mice, but not in adult animals [4, 14, 15], leading to the conclusion that this alternative splice variant could have a developmental function. Alternative splicing of the GAD67 gene has also been demonstrated in cells of adult human pancreatic islets. Exon 7 was inserted after exon 6 of
GAD67, resulting in a shorter transcript of GAD67 mRNA, encoding GAD25 [3].

The potential role of $G A D$ in pancreas development [4, 16] and the lack of knowledge of the normal expression of different $G A D$ isoforms during normal fetal pancreas development led us to investigate $G A D$ expression at the mRNA level in a series of human fetal pancreas specimens of 14 weeks gestation until term. In this paper, we demonstrate GAD67 and GAD67 splice variants, including GAD25 mRNA expression by RT-PCR, between 14 weeks gestation and term and in the adult pancreas.

\section{Materials and Methods}

Tissue Specimens

Human fetal $(n=14)$ and adult $(n=4)$ pancreatic specimens were retrieved from the Erasmus MC Tissue Bank, Department of Pathology, Rotterdam, The Netherlands, following approval of the experimental design and protocols by the Medical Ethical Committee. The fetuses had died of causes not related to the pancreas. Autopsy was performed within $24 \mathrm{~h}$ after death. The adult pancreatic tissue was obtained from normal tissue in pancreatic
Fig. 1 A Schematic representation of exon 6 to exon 10 of GAD67, including the localization of the primers used for the $\mathrm{RT}$ reaction (GAD67.Ar) and PCR (GAD25.1f, GAD25.1r, GAD67.1f, and GAD67.1r). In the adult form, exon 7 is spliced out of the mRNA, but in embryonic mouse brain, a part of exon 7 is spliced out in two different ways. Either the first $80 \mathrm{bp}(\mathrm{I}-80)$ or the first $86 \mathrm{bp}$ (I-86) is retained in the mRNA, and because an overlapping translation stop-start sequence occurs after 34 nucleotides in exon 7, the I-80 and I-86 inserts result in two "open reading frames" (ORFs) and one ORF, respectively, as displayed in subpanel (B). B Overview of alternative mRNA splice variants, including the predicted ORFs; ORF1 encodes GAD67, ORF2 encodes GAD25, whereas ORF3 encodes GAD44. The additional $6 \mathrm{bp}$ in the I-86 message contains an in-frame stop codon which abolishes the translation of GAD44

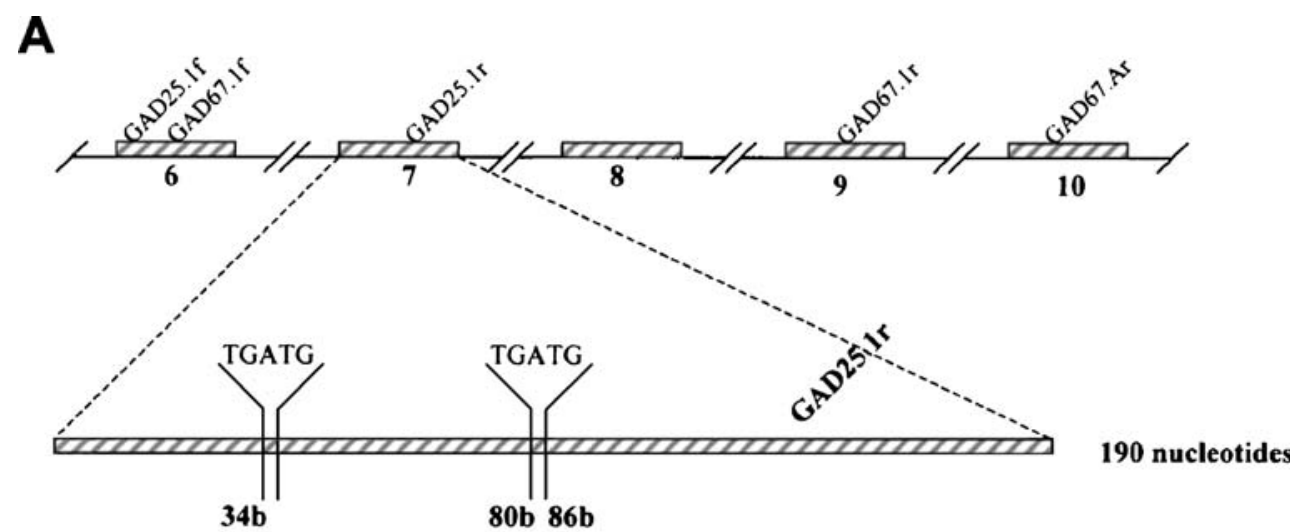

B
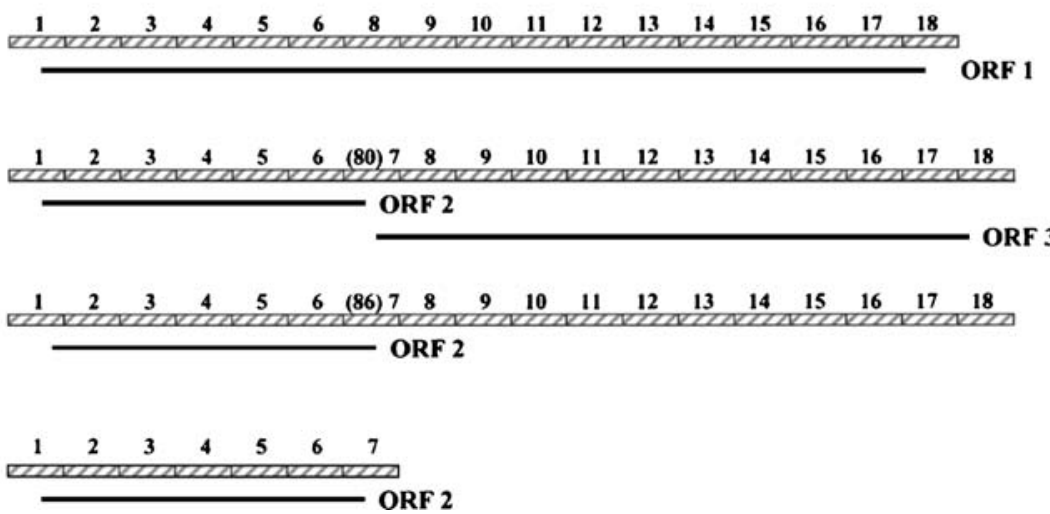
resection specimens. Histological analyses confirmed the presence of normal tissue in these adult pancreas samples.

Fourteen snap-frozen pancreatic samples between 14 weeks gestation and term (gestational ages: 14, 16, 18, $19,21,26,27,29,32(n=2), 33,36$, and $40(n=2)$ weeks, respectively) and four adult snap-frozen pancreatic samples were stored in liquid nitrogen and were used to isolate RNA. Paraffin samples were fixed by immersion in $4 \%$ buffered formaldehyde and embedded in paraffin according to the standard procedures.

\section{RNA Isolation}

Total RNA was extracted using Trizol reagent (Life Technologies, Rockville, MD, USA) following the manufacturer's instructions. After RNA isolation, the quality of $5 \mu \mathrm{g}$ RNA was checked with an MOPS gel $(0.2 \mathrm{M} 3-\mathrm{N}$ morpholinepropanesufonic acid, $0.05 \mathrm{M}$ sodium acetate, and $0.01 \mathrm{M} \mathrm{Na}_{2}$ EDTA).

cDNA Synthesis and PCR Amplification

One microgram of total RNA from 18 pancreases was reverse-transcribed with a mix of specific reverse primers for GAD67 (5'-AGTGACTCTGTTCTGAGGTG-3'), POLR2A (5'-TTGTTAGAGTCCACAAGCAG-3'), and oligo-dT (T12). cDNA synthesis was performed in a final volume of $20 \mu \mathrm{l}$ containing $50 \mathrm{mM}$ Tris- $\mathrm{HCl}(\mathrm{pH} 8.3$ ), $75 \mathrm{mM} \mathrm{KCl}, 3 \mathrm{mM} \mathrm{MgCl} 2,10 \mathrm{mM}$ DTT, $3 \mathrm{pM}$ specific primer mix, $1 \mathrm{mM}$ dNTPs, $200 \mathrm{U}$ Moloney murine leukemia virus (M-MLV) reverse transcriptase (Invitrogen, San Diego, CA, USA), and $30 \mathrm{U}$ RNase inhibitor (Promega, Madison, WI, USA). The RT mix was incubated for $1 \mathrm{~h}$ at $37^{\circ} \mathrm{C}$. Polymerase chain reaction was performed with $1 \mu \mathrm{l}$ cDNA in a final volume of $15 \mu$ l containing $1.5 \mathrm{mM} \mathrm{MgCl} 2 ; 10 \mathrm{mM}$ Tris- $\mathrm{HCl} ; 50 \mathrm{mM} \mathrm{KCl} ; 0.02 \mathrm{mM}$ dATP; $0.2 \mathrm{mM}$ dGTP, dTTP, and dCTP; $0.8 \mu \mathrm{Ci} \alpha^{32} \mathrm{P}-$ dATP (Amersham, Buckinghamshire, United Kingdom), 15 pmol of each forward and reverse primer for GAD67 and POLR2A (Table 1), and $1 \mathrm{U}$ Taq polymerase (Promega, Madison, WI, USA). PCR was performed for 35 cycles at $95^{\circ} \mathrm{C}$ for $30 \mathrm{~s}, 58^{\circ} \mathrm{C}$ for $45 \mathrm{~s}$, and $1 \mathrm{~min}$ at $72^{\circ} \mathrm{C}$, followed by 1 cycle at $72^{\circ} \mathrm{C}$ for $10 \mathrm{~min}$. PCR products were run on a denaturing $6 \%$ polyacrylamide gel (Fluka, Neu-Ulm, Germany). After electrophoresis, the gel was dried and exposed to an x-ray film. Negative controls for the RT reaction were performed by omission of either M-MLV reverse transcriptase or RNA, and for the PCR by omission of cDNA.

\section{DNA Sequencing}

To confirm that the additional bands represented both splicing forms, two $50 \mu \mathrm{l}$ PCRs were performed with two cDNA samples, respectively, at 14 and 19 weeks. Polymerase chain reaction was performed under the identical conditions as the previous PCR except that this mix contained $0.2 \mathrm{mM}$ dNTPs instead of $0.02 \mathrm{mM}$ dATPs and $0.8 \mu \mathrm{Ci} \alpha^{32} \mathrm{P}$-dATP. The PCR products were run on a $2 \%$ agarose gel, and the additional bands were excised out of the gel and purified using a QIAquick Gel Extraction Kit (Westburg, Leusden, The Netherlands) according to the manufacturer's instructions. The purified PCR products were commercially sequenced (Baseclear, Leiden, The Netherlands).

\section{Results}

\section{RT-PCR}

The housekeeping gene POLR2A was used as a positive control for the RT reaction and showed positive results for all samples (Fig. 2A). Using the GAD67 primers, four distinct PCR products per sample were observed. In all samples, a 200-bp amplified product was present, which represents the adult GAD67 isoform, without insertion of exon 7 . The 280 -bp product and the 286 -bp product were highly reproducible and detected in most fetal and all adult samples (Fig. 2C). Three fetal pancreatic samples showed only the 286-bp additional band. An additional PCR product of about 330-bp appeared reproducibly in the majority of samples. This product was sequenced, as well as the 280-bp and the 286-bp PCR products (see below). To detect the GAD25 mRNA, we performed PCR with specific primers for $G A D 25$, i.e., a forward primer in exon 6 and a reverse primer in the last part of exon 7 (Fig. 1). The results show an expression of this GAD25 form in all fetal and adult pancreas specimens (Fig. 2C). In general, there appeared to be no differences in expression levels by RT-

Table 1 Primers used for PCR

\begin{tabular}{llll}
\hline Specificity & Forward (5'-3') & Reverse (5'-3') & Expected product size \\
\hline GAD67 & gagaatggctgacatcaacg & gaagtacttgtagcgagcag & $200 \mathrm{bp}$ \\
GAD25 & tttcaaccagctctcca & tgcagttaccatcacctctg & $189 \mathrm{bp}$ \\
POLR2A & cggatgaactgaagcgaatg & ttgttagagtccacaagcag & $188 \mathrm{bp}$ \\
\hline
\end{tabular}


Fig. 2 A-C Results of RT-PCR experiments of seven representative samples, with primers against POLR2A (A), GAD67 (B), and GAD25 (C). The arrows indicate the sizes of the PCR products, which are $188 \mathrm{bp}$ for POLR2A (A); 200, 280, and 286 bp for GAD67, respectively (B); and 189 bp for GAD25 (C)

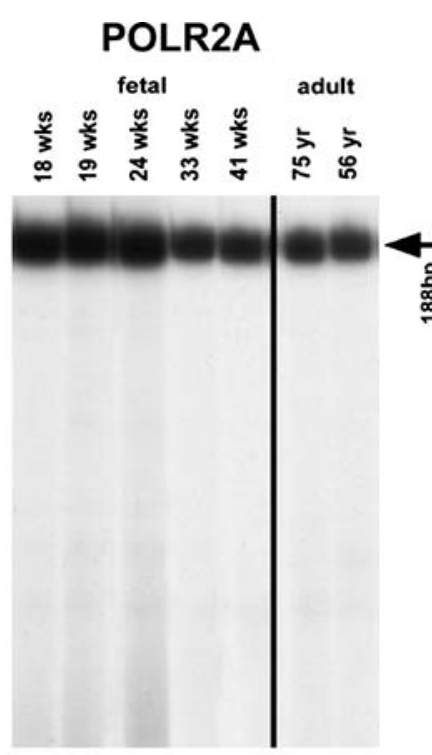

A

PCR between the different gestational ages or the adult samples for all of the primer combinations used.

Sequence Analysis

Sequence analysis with specific forward and reverse primers revealed that the two additional PCR products of 280 and 286 bp consisted of the adult form with an insertion of either the first 80 or $86 \mathrm{bp}$ of exon 7. The additional product of $330 \mathrm{bp}$ (Fig. 3), consisting of exons 6 to 9, with an insertion of $68 \mathrm{bp}$ between exons 6 and 7 (Fig. 4), appeared to be a new splice product. This new exon was flanked by authentic splice junctions: 5'-AG/GT-3'. The additional sequence was homologous to a part of intron 6 of the human GAD67 gene (51.128-51.195 of GenBank $^{\mathrm{TM}}$ accession number AC007405). The first 213 amino acids of the predicted protein are homologous to GAD25,

Fig. 3 Four distinct RT-PCR products appear when GAD67 primers are used in this human fetal pancreas of 16 weeks of gestation. In lane 1 , the native GAD67 PCR product of $200 \mathrm{bp}$ is seen. Lane 2 represents the PCR products of the I- 80 and I-86 splice variants, whereas lane 3 shows the newly found PCR product of $330 \mathrm{bp}$

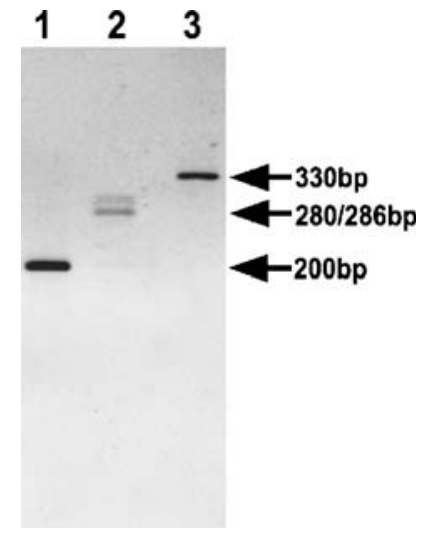

followed by another 26 amino acids. The predicted molecular weight would approximately be $29.3 \mathrm{kDa}$.

\section{Discussion}

The potential role for $G A D$ in pancreas development and the lack of knowledge about the distribution of the isoforms and splice variants of $G A D$ led us to investigate GAD67 and $G A D 25$ expression in the human fetal pancreas. We performed RT-PCR, on human fetal and adult pancreases, and found mRNA expression of GAD67 and GAD25 from 14 weeks gestation onward until term, as well as in the adult pancreas specimens. Apart from the adult form of GAD67, the RT-PCR experiments revealed three additional splice variants, which have not been described previously in the human pancreas.

Our study revealed GAD67 mRNA expression in all fetal and adult pancreases. Whereas GAD67 expression at the mRNA and protein level is well established in the mouse pancreas, only a few studies, using RNA protection assay analysis and RT-PCR, have demonstrated GAD67 mRNA expression in the human pancreas [11, 17]. In contrast, GAD67 was never detected in the human pancreas at the protein level, although some studies found GAD67 autoantibodies in type 1 diabetes mellitus patients, in the absence of GAD65 autoantibodies [5-7]. An explanation for the negative findings of previous studies could be that the GAD67 protein has already degraded because the halflife of the GAD67 protein is less than $4 \mathrm{~h}$ [18].

According to the literature, alternative splicing of the GAD67 gene results in at least four mRNA products [3, 4]. 
Fig. 4 Forward sequence of the additional PCR product of $330 \mathrm{bp}$

\author{
exon 6 \\ new exon \\ ACCAACAT | GTCATGGTTAGCTTCACAGACTGTCCATGTTGGGTCACTGAGATTTGGAAGA \\ exon 7 \\ GCCAAGAGGAATACAG | GCCATCAGACATGAGGGAGTGTTGGTTGCTACGGTGATGGGGCT \\ CAGAGCAGAACCAAAGCATGATTGTGACCTCCAGAGGTGATG | GTTTACATATGAAATTGC \\ exon 8 \\ ACCAGTGTTTGTCCTCATGGAACAAATAACACTTAAGAAGATGAGAGAGATAGTTGGATGG \\ exon 9 \\ TCAAGTAAAGATGGTGATGGGATATTTTCTCCTGG| GGGCGCCATATCCAACATGTACAGC
}

\section{ATCATGGCTGCTCGCTACAAGTACTTC}

In our study, we demonstrate four GAD67 mRNA isoforms in the human fetal and adult pancreas samples. The first discovered transcript was an mRNA product, which lacks exon 7 and encodes for the native 67-kDa protein (GAD67) (see the "Results" section). A second transcript comprised the first seven exons of the GAD67 gene, encoding a 25 $\mathrm{kDa}$ protein $(G A D 25)$. This variant was previously reported in human nonneural tissues by Chessler et al. [19]. A third and fourth transcript contained the first 80 or 86 bp of exon 7. So far, these mRNA variants have only been described in embryonic mouse brain [3, 4]. In contrast to the mouse brain, where the GAD67 mRNA splice variants seem to have a developmentally regulated expression pattern [4], we did not see an increase of the 80-bp splice form, nor did we detect a decrease of the 86-bp during gestation, compared to each other in the same sample. In addition, all different mRNA isoforms described above were detected in most human fetal pancreases from 14 weeks of gestation until term even in the adult pancreases. It should be noted, though, that these experiments were not set up to yield quantitative data and therefore must be interpreted with caution.

The additional RT-PCR product of $330 \mathrm{bp}$ represents a heretofore undescribed splice variant of GAD67, with an insertion of an unknown exon before the I-86 insert. The predicted protein would consist of 213 amino acids, of which the first part consists of the same amino acids as $G A D 25$, followed by another 26 amino acids, and would have a molecular weight of approximately $29 \mathrm{kDa}$. Szabo et al. [4] observed two isoforms of approximately 31 and $32 \mathrm{kDa}$ in embryonic mouse brain by Western blot. These products were assumed to be the result of posttranslational modifications. The predicted protein of our newly found splice variant might actually represent one or both of the proteins found by Szabo et al. [4].

In summary, we found GAD67 mRNA expression during the entire gestational period investigated. In addition, GAD67 splice variants were present in both fetal and adult pancreases. We also found a heretofore undescribed GAD67 mRNA splice variant, which is also found in the fetal and adult pancreases. These results suggest that GAD67 and its splice variants might play a role in the developing human fetal pancreas and in the maintenance of the human adult pancreas.

Acknowledgments We are grateful to the Erasmus MC Tissue Bank (Department of Pathology, Rotterdam, The Netherlands) for providing human fetal and adult frozen pancreas tissue. We gratefully acknowledge Frank van der Panne (Department of Pathology, Josephine Nefkens Institute, Erasmus MC, Rotterdam, The Netherlands) for his assistance with the generation of the figures. This study was supported by a grant from the European Union QLRT-1999-00276 (MONODIAB). The authors declare that there is no conflict of interest that would prejudice the impartiality of this scientific work.

\section{References}

1. Bu DF, Erlander MG, Hitz BC, Tillakaratne NJ, Kaufman DL, Wagner-McPherson CB, et al. Two human glutamate decarboxylases, 65-kDa GAD and 67-kDa GAD, are each encoded by a single gene. Proc Natl Acad Sci U S A 89:2115-9, 1992.

2. Martin DL, Liu H, Martin SB, Wu SJ. Structural features and regulatory properties of the brain glutamate decarboxylases. Neurochem Int 37:111-9, 2000.

3. Chessler SD, Lernmark A. Alternative splicing of GAD67 results in the synthesis of a third form of glutamic-acid decarboxylase in human islets and other non-neural tissues. J Biol Chem 275:518892, 2000.

4. Szabo G, Katarova Z, Greenspan R. Distinct protein forms are produced from alternatively spliced bicistronic glutamic acid decarboxylase mRNAs during development. Mol Cell Biol 14:7535-45, 1994.

5. Falorni A, Ackefors M, Carlberg C, Daniels T, Persson B, Robertson J, et al. Diagnostic sensitivity of immunodominant epitopes of glutamic acid decarboxylase (GAD65) autoantibodies in childhood IDDM. Diabetologia 39:1091-8, 1996.

6. Grubin CE, Daniels T, Toivola B, Landin-Olsson M, Hagopian WA, Li L, et al. A novel radioligand binding assay to determine diagnostic accuracy of isoform-specific glutamic acid decarboxylase antibodies in childhood IDDM. Diabetologia 37:344-50, 1994.

7. Kaufman DL, Erlander MG, Clare-Salzler M, Atkinson MA, Maclaren NK, Tobin AJ. Autoimmunity to two forms of glutamate decarboxylase in insulin-dependent diabetes mellitus. J Clin Invest 89:283-92, 1992. 
8. Kim J, Richter W, Aanstoot HJ, Shi Y, Fu Q, Rajotte R, et al. Differential expression of GAD65 and GAD67 in human, rat, and mouse pancreatic islets. Diabetes 42:1799-808, 1993.

9. Mally MI, Cirulli V, Otonkoski T, Soto G, Hayek A. Ontogeny and tissue distribution of human GAD expression. Diabetes 45:496-501, 1996.

10. Petersen JS, Russel S, Marshall MO, Kofod H, Buschard K, Cambon N, et al. Differential expression of glutamic acid decarboxylase in rat and human islets. Diabetes 42:484-95, 1993.

11. Cram DS, Faulkner-Jones B, Kun J, Harrison LC. Glutamic acid decarboxylase-67 (GAD67): expression relative to GAD65 in human islets and mapping of autoantibody epitopes. Endocrinology 136:1111-9, 1995.

12. Li L, Jiang J, Hagopian WA, Karlsen AE, Skelly M, Baskin DG, et al. Differential detection of rat islet and brain glutamic acid decarboxylase (GAD) isoforms with sequence-specific peptide antibodies. J Histochem Cytochem 43:53-9, 1995.

13. Faulkner-Jones BE, Cram DS, Kun J, Harrison LC. Localization and quantitation of expression of two glutamate decarboxylase genes in pancreatic beta-cells and other peripheral tissues of mouse and rat. Endocrinology 133:2962-72, 1993.
14. Bond RW, Wyborski RJ, Gottlieb DI. Developmentally regulated expression of an exon containing a stop codon in the gene for glutamic acid decarboxylase. Proc Natl Acad Sci U S A 87:8771-5, 1990.

15. Szabo G, Kartarova Z, Hoertnagl B, Somogyi R, Sperk G. Differential regulation of adult and embryonic glutamate decarboxylases in rat dentate granule cells after kainate-induced limbic seizures. Neuroscience 100:287-95, 2000.

16. Soghomonian JJ, Martin DL. Two isoforms of glutamate decarboxylase: why? Trends Pharmacol Sci 19:500-5, 1998.

17. Kawasaki E, Moriuchi R, Watanabe M, Saitoh K, Brunicardi FC, Watt PC, et al. Cloning and expression of large isoform of glutamic acid decarboxylase from human pancreatic islet. Biochem Biophys Res Commun 192:1353-9, 1993.

18. Michelsen BK, Petersen JS, Rambrandt TB, Boel E, Karlsen AE, Videbaek $\mathrm{N}$, et al. Differential islet cell expression of two glutamate decarboxylases, both autoantigens in diabetes. Biochem Soc Trans 21:173-7, 1993.

19. Chessler SD, Hampe CS, Ortqvist E, Simonson WT, Bekris L. Immune reactivity to GAD25 in type 1 diabetes mellitus. Autoimmunity 35:335-41, 2002. 